\title{
PLANIFICACIÓ (ECO)LINGÜÍSTICA I GESTIÓ DELS INTERCANVIS LINGÜÍSTICS
}

\author{
Oscar Diaz Fouces \\ Universidade de Vigo
}

\section{Resum}

Lautor presenta un ventall de polítiques orientades a mantenir la integritat dels espais ecolingüístics, relacionades amb la traducció, amb l'ensenyament de llengües, amb l'intercanvi de productes culturals i, en general, amb la gestió dels intercanvis lingüístics.

\begin{abstract}
The author presents a range of policies aimed at maintaining the integrity of the ecolinguistic spaces related to translation, language teaching, to the exchange of cultural products and, in general, to the management of linguistic interchanges.
\end{abstract}

\section{Paraules clau}

Planificació lingüística. Ecolingüística. Globalització. Polítiques de traducció. Gestió lingüística. Formació lingüística.

\section{Keywords}

Language planning. Ecolinguistics. Globalization. Translation policies. Language management. Language training. 


\section{Preliminars}

\subsection{L'aproximació racional als fenòmens socials}

Linterès per l'estudi científic de la racionalització de les actuacions públiques va néixer probablement als Estats Units, en els anys posteriors a la Segona Guerra Mundial, el mateix moment que començava a expandir-se l'organització científica de la producció empresarial (el taylorisme i el fordisme). Va ser aleshores que alguns think tanks amb gran influència van començar a aplicar a la recerca social unes perspectives multidisciplinàries que havien estat poc freqüents. Els nous enfocaments utilitzats, basats en la racionalitat científica, incloïen instruments heurístics molt novedosos, com l'anàlisi estratègica, la cibernètica o la teoria dels jocs. Un del casos més coneguts és el de la Rand Corporation, els treballs de la qual van inspirar -i continuen inspirant- decisions molt importants, relacionades amb la salut pública, amb la prevenció del terrorisme, amb el desenvolupament de la xarxa Internet o, fins i tot, amb l'exploració espacial.

En aquest context cal situar, per exemple, l'aparició de disciplines com el (Public) Policy Analysis (que, amb prevencions, podem fer correspondre amb la traducció Anàlisi de les polítiques públiques), que van representar un nou model per a l'estudi de l'acció dels governs i de les administracions. Com afirma Robert H. Haveman (1987), la investigació tradicional en l'àmbit de les ciències socials havia estat fonamentalment de caire positiu (intentava descriure la realitat), abans de l'aparició del Policy Analysis, que representaria un biaix normatiu (pretenia intervenir sobre la realitat). Lexemple que proposa és molt entenedor: la investigació sociològica tradicional s'ocuparia dels comportaments il-legals intentant averiguar-ne l'extensió, bé com la naturalesa, les causes i les conseqüències; el nou enfocament, en canvi, analitzaria les mesures disponibles per reduir aquests comportaments i les avaluaria en funció de llur eficàcia, entesa com la relació òptima entre el cost esmerçat i el benefici aconseguit. 


\subsection{La Planificació Lingüística}

Aquesta mena d'aproximació als fenòmens socials va arribar a abastar també aquell que és, potser, el tret més característic de l'espècie humana: l'ús de les llengües. Com observava Heinz Kloss (1967), les llengües no neixen i moren com les plantes, sinó que també poden ser (i tot sovint són) l'objecte d'intervencions humanes, i aquestes es poden racionalitzar i poden prendre la forma de programes organitzats. Si considerem que les llengües són instruments comunicatius i representacionals (més enllà de la seva condició de sistemes semiòtics abstractes), sembla clar que aquestes actuacions sobre elles $i$ les decisions que les han motivat afectaran l'activitat quotidiana de les persones que les fan servir $i$, aleshores, que representaran una forma d'enginyeria social. Les decisions i les actuacions a les quals ens referim són l'objecte d'interès d'una disciplina que és habitual de designar amb el nom de Planificació Lingüística i que és, precisament, un bon exemple d'instrument conceptual relacionat amb la racionalització de les actuacions públiques. En efecte, el propòsit de la Planificació Lingüística també és decididament normatiu i no pas positiu. Deixant de banda la descripció de la realitat lingüística, que és pròpia d'unes altres disciplines (com ara la Morfologia, la Sintaxi o, en uns altres nivells, la Pragmàtica o l'Anàlisi del Discurs), el seu objectiu declarat és provocar alguna mena de transformació en les pràctiques lingüístiques d'alguna comunitat humana i, doncs, un canvi social (vg. Cooper 1989).

La Planificació Lingüística va néixer als anys seixanta del segle passat. Significativament, una de les trobades fundacionals de la nova disciplina, l'Airlie House Conference, que tingué lloc a Virgínia l'any 1966 (vg. els materials publicats a Fishman, Ferguson \& Das Gupta 1968) va tenir com a tema estrella, en el marc de la postguerra mundial, els problemes lingüístics de les nacions en vies de desenvolupament. Aquests problemes tenien a veure amb l'estudi dels processos que menen a la constitució de les llengües estàndard, incloenthi la codificació (lexical, gramatical, ortogràfica) i l'anàlisi de les situacions de llengües en contacte, és a dir la coexistència de comunitats lingüístiques diferents en un mateix territori físic. En realitat, la nova disciplina de la Planificació Lingüística va néixer amb un notable caràcter prescriptiu: ja que la llengua és un element cohesionador i homogeneitzador de primer ordre per a les societats humanes, la configuració de sistemes lingüístics homogenis (l'estàndard) i la gestió racional de la diversitat (l'ordenació del multilingüisme) havien de ser també eines essencials per a les nacions emergents.

Epistemològicament, l'estudi de les qüestions relacionades amb la racionalització dels processos sociolingüístics (l’àmbit de la Planificació Lingüística) s'ha bastit a partir de contribucions de caire "més lingüístic," especialment 
aquelles que afecten els aspectes estructurals. Això explicaria la filiació acadèmica de bona part dels seus conreadors. Tot plegat no hauria impedit mai, ans al contrari, que hagin rebut sempre una atenció preferent per part de la Sociologia més instituilda, com ho demostra la inclusió d'apartats sobre Llengua i Societat en manuals, programes acadèmics, i trobades d'investigació en aquest marc disciplinar. Per exemple, el Research Committee 25 para el XVII congrés mundial de la International Sociological Association, convocat per al 2010, a http://www.isa-sociology.org/congress2010/rc/rc25.htm, inclou, entre d'altres, sessions dedicades a "Sociology and Language" i a "Minority Languages and Language Policy".

Com a instrument metodològic, la Planificació Lingüística pot ser considerada "neutra". Efectivament, no hi ha cap motiu perquè la racionalització de les actuacions sobre un marc sociolingüístic determinat sigui intrínsecament "progressista" o "reaccionària", ni tampoc "bona" o "dolenta". És evident, però, que els resultats d'aquest tipus d'intervencions (com ara la substitució d'una llengua per una altra a l'ensenyament i els àmbits públics, la priorització d'un dialecte sobre la resta per dissenyar l'estàndard o la substitució d'un sistema de representació ortogràfica) no passen desapercebuts de cap manera i que, per descomptat, poden reportar beneficis o perjudicis als grups humans que els experimenten.

Malauradament, la Planificació Lingüística no ha ocupat gaire dels assumptes relacionats amb la Traducció (vg. Toury 1999). Amb tot i això, és evident que qualsevol procés de gestió lingüística hi té un paper destacat, molt més encara en el món globalitzat actual, com després veurem. Val a dir que la Planificació Lingüística tampoc no ha estat un marc teòric massa sovintejat des dels Estudis de Traducció. Amb tot i això, ens sembla evident que hi ha un lloc de confluència molt clar entre totes dues disciplines, precisament en l'àmbit d'una Sociologia de (o aplicada a) la Traducció (vg. Diaz Fouces 1996). Com apuntava Chesterman (2006: 17) en un treball recent que intentava cartografiar aquest últim espai:

Finally, mention should be made of work in language planning, which is directed towards the application of research-based knowledge to particular social situations and problems. Typical issues concern language and/or translation policies in multilingual countries or institutions, or for minority languages. These issues have obvious relevance for language rights, democracy and political development, all of which lie within the sphere of sociological interest. 


\subsection{La perspectiva ecolingüística}

Lestudi de la racionalització dels processos sociolingüístics ha donat lloc a orientacions més específiques, com ara l'anomenada Ecolingüística. L'obra que s'ha guanyat la condició de fundacional en l'ús de la metàfora ecològica aplicada a l'àmbit lingüístic és el treball d'Einar Haugen "The Ecology of Language" (Haugen 1972), basat en una conferència impartida l'any 1970. La definició per al concepte que donava nom a l'article era, literalment, "the study of interactions between any given language in its environment". Divuit anys més tard, el 1990, trobem un altre treball seminal (Halliday 1990), que enceta una línia d'investigació interessada en el paper que juga el llenguatge en l'agreujament o la solució dels problemes ambientals i, per extensió, en els altres problemes socials. També és habitual d'acceptar que totes dues línies sintetitzen, d'una manera complementària -i, per tant, no excloent- el camp d'allò que coneixem com Ecolingüística (cf. Fill 1998). La segona, clarament, està associada amb el marc teòric de l'Anàlisi Crítica del Discurs. La primera, la que a nosaltres ens interessa en aquest moment, podria ser caracteritzada a partir d'alguns paràmetres que permeten identificar el "pensament ecològic", com ara la voluntat de prendre en consideració els factors externs (ambientals) en l'anàlisi dels sistemes lingüístics, i no només els interns; observar els problemes que genera la unilateralitat de les monocultures; deixar d'obviar el fet que els recursos naturals i les capacitats humanes no són pas il-limitats; i abandonar les perspectives a curt termini en l'anàlisi i la intervenció sobre les llengües (Weinrich 2001: 94; cf. Muhlhäusler 2000: 308).

Algunes de les preguntes que es poden formular des d'aquesta mena d'aproximació són prou significatives: quina és la funció de la diversitat lingüística i cultural?, de quins mecanismes depèn?, es possible optimitzarla? Convé recordar, per cert, que també existeix alguna orientació en l'àmbit de la Planificació Lingüística (especialment una determinada tradició americana), que no s'ha interessat d'una manera especial per la gestió de la diversitat i que ha prioritzat, de manera significativa, l'estudi de conceptes com el d'estandardització. És clar que aquesta mena de perspectiva no s'adiu massa bé amb el paradigma ecològic. Com apunta Mühlhäusler (2000: 310), de vegades "The solution to the adherents of the ecological approach is the problem to most traditional language planners".

Un bon exemple de trencament de l'equilibri ecolingüístic és l'anomenada subordinació lingüística, una situació de desequilibri social entre dues o més comunitats humanes, la principal dimensió explícita de la qual és alguna mena de restricció d'alguna o d'algunes de les pràctiques lingüístiques del(s) grup(s) subordinat(s), en favor de les pràctiques del(s) grup(s) hegemònic(s). 
Les llengües en situació subordinada tendeixen a patir una important degradació estructural que les inhabilita progressivament com a instruments eficaços de comunicació. De vegades, la interferència de la llengua dominant mena a una depauperació del sistema estilístic propi en favor dels usos d'aquella que comporta una autèntica hibridació (eventualment, una criollització). En termes d'ús, es caracteritzen pel fet de patir una intromissió constant de la llengua dominant en tots els espais d'ús, que comporta una funcionalitat limitada i restringida. Tot plegat constitueix una mena de cercle viciós que retroalimenta i agreuja la subordinació. L'ús d'aquests codis comporta sovint per a les persones que els fan servir algun tipus d'estigma social (és un ús marcat), circumstància que n'afavoreix la deserció i que dificulta l'atracció dels nous usuaris. Els exemples poden ser molt variats, com també les circumstàncies en què es produeix: l'occità a França, el català a Itàlia, el turc a Alemanya i l'espanyol als Estats Units d'Amèrica comparteixen el caràcter subordinat, però és evident que els símptomes i les situacions respectives, així com les possibilitats de suportar o fins i tot de revertir la subordinació són força diferents. La situació del català no és pas la mateixa a Itàlia que a Espanya (malgrat que estigui subordinat a tots dos estats); la situació del turc a Turquia (on és llengua dominant) és ben diferent de la seva situació a Alemanya; i, òbviament, les situacions globals de l'occità i de l'espanyol no tenen res a veure.

La metàfora ecològica identificaria totes aquestes circumstàncies amb la desestructuració de l'hàbitat ecolingüístic d'un grup humà. I, com assenyala Bastardas (2000), el manteniment de la diversitat lingüística no tindria tant a veure amb la posada a la pràctica de mesures centrades en les llengües amenaçades, com en la creació de nous contextos adaptats a les noves situacions, capaços d'estimular la continuitat del seu ús. És a dir: la (re)generació dels hàbitats ecolingüístics adequats. En una línia semblant, de Swaan (2001: 54) suggereix que:

A biological species [...] may be saved by safeguarding the environment where it finds its niche. For a language to survive, a considerable number of people must maintain their speech and maybe their ways of life against the inroads of a changing social and linguistic environment - a rather more formidable task.

Cal tenir sempre en compte, en tot cas, que ens estem referint a processos socials, en què els protagonistes són éssers dotats de raciocini, la qual cosa suposa una important restricció ètica i un límit a les aplicacions més simplistes de la metàfora ecològica. S. Mufwene ha criticat el cinisme d'una determinada lingüística, que s'entossudeix a encoratjar els parlants de llengües en vies d'extinció, especialment al tercer món, perquè les continuïn fet servir 
només en nom del "manteniment de la diversitat lingüística", encara que sigui evident que la migració lingüística pot millorar llur condició socioeconòmica. Com assenyala en un interessant treball (Mufwene 2002: 42):

Languages die gradually and inconspicuously as a consequence of the communicative practices of the relevant population, in ecologies where the speakers themselves can be considered as victims, as they themselves have adapted to change. We cannot just encourage them to maintain their ancestral languages even if only as home varieties without providing the ecologies that can support our prescriptions.

En aquest treball assumim que la gestió racional dels ecosistemes lingüístics, la planificació ecolingüística, és un valuós instrument de regulació de l'equilibri ecolinguístic i, complementàriament, que les polítiques en què es fa explícita, que inclouen necessàriament les polítiques de traducció, poden ser, com veurem, una eina de primer ordre per aquesta comesa.

\section{L'economia lingüística, la globalització i les noves regles del joc}

Aquest que acabem de presentar és el marc global en què es vol situar aquest treball. Abans d'avançar més, però, caldrà que ens aturem a fer algunes consideracions, conceptuals i contextuals, per acabar-ho d'afinar.

\subsection{La globalització i el globalisme}

Hem de considerar, d'entrada, que en els últims anys es fa cada cop més difícil parlar de sistemes ecolingüístics particulars. A la pràctica, la nostra espècie està arribant al punt de constitució d'una constel-lació mundial de llengües (cf. de Swaan 2001), un nou sistema (eco)lingüístic global, i cap anàlisi sociolingüística no pot obviar aquesta circumstància. Els límits dels estats-nació han guanyat permeabilitat, tant pel que fa als intercanvis econòmics, com als comunicatius (encara que aquesta condició no sempre s'hagi estès a la lliure circulació de les persones). Els antics mercats nacionals s'han organitzat en xarxes globals i els consumidors potencials són ara a tot arreu. Globalització és l'etiqueta utilitzada per descriure aquest estat de les coses, que inclou també (cf. Santos 2006) una economia dominada per un sistema financer i inversor d'escala global, uns processos de producció flexibles i ubics, unes polítiques fiscals i monetàries orientades a la contenció de la inflació, una reducció de les despeses de transport, una revolució en les tecnologies de la informació i de les comunicacions i una mínima intervenció estatal en les economies locals (incloent-hi la limitació de les despeses en polítiques socials i la privatització dels sectors empresarials). 
Com tots els canvis socials massius, la globalització no pot ser entesa sense el rerefons ideològic que hi dóna suport. Steger (2005) utilitza el terme globalisme per fer referència a la ideologia de la globalització, que destillla assercions que ens resultaran tan familiars com aquestes: la globalització implica la liberalització i la integració global dels mercats (de fet, com apunta Fairclough [2006], el globalisme identifica la globalització amb l'extensió del lliure mercat); la globalització és inevitable i irreversible alhora; la globalització no és patrimoni de ningú; la globalització és un procés beneficiós per a tothom; la globalització facilita l'extensió de la democràcia a tot arreu. El corol-lari econòmic del globalisme, que complementa la primera asserció, és el neoliberalisme, una ideologia/utopia que prioritza el paper dels mercats sobre el paper dels estats, l'individu sobre la collectivitat, i que preconitza la mercantilització (commodification) de totes les coses, incloent-hi l'accés als processos polítics.

\subsection{La llengua com a bé}

Si aquestes que acabem de presentar són algunes de les noves regles del joc, de quina manera afecten la dinàmica ecolingüística? Podem començar per suposar que l'intent de reduir l'abast d'algunes categories clàssiques com la de subordinació lingüística als límits d’un estat-nació concret és, probablement, un exercici estèril: en el nou sistema global l'equilibri ecolingüístic també serà global, així com el risc de desestabilització dels sistemes ecolingüístics particulars, i condicionarà potencialment tant les llengües hegemòniques com les subordinades (encara que, ben segur, amb diferent intensitat).

La primera qüestió que hauríem d'abordar, per tal d'analitzar el funcionament d'aquest "nou ordre" és la del paper que correspon a les llengües, en un mercat global. D'acord amb Grin (1994: 35), recordarem que, en l'ús corrent que en fan els estudis econòmics, un mercat es defineix a partir de quatre elements: un producte (commodity) -tant si és un bé com un servei- clarament definit; un preu per al mateix, ben establert; una previsió de la demanda, que representa el volum de bé/servei que els agents estan disposats a consumir, per a cada tram de preus; i una previsió de l'oferta, que identifica el volum de bé/servei que els agents estan disposats a produir, també per a cada tram de preus.

2.2.1. La llengua-coneixement com a capital humà i com a bé hipercol-lectiu La caracterització de la llengua com a producte presenta, però, algunes peculiaritats interessants. Podem constatar, per començar, que les llengües són 
béns col-lectius perquè ningú no pot ser exclòs del seu ús i, alhora, perquè l'esforç d'un únic individu no és suficient per mantenir-los. D'altra banda, la llengua entesa com a bé presenta la característica òbvia de no esgotar-se a mesura que es consumeix. Si allò més habitual és que l'increment del consum dels béns n'augmenti la raritat (i, per tant, el preu), en el cas de la llengua, paradoxalment, el valor augmenta a mesura que n'augmenta l'ús, sense que es produeixi cap minva de la quantitat total de producte disponible. El concepte d'externalitats de xarxa (network externalities, vg. Katz \& Shapiro 1986) fa referència a aquells béns que augmenten la utilitat que tenen per als individus a mesura que augmenta el nombre de persones que els consumeixen. Ens estem referint, és clar, al coneixement d'una llengua com un bé, o si voleu, com allò que Chiswik \& Miller (1995: 248) anomenen un capital humà:

Language skills are an important form of human capital. They satisfy the three basic requirements for human capital: they are embodied in the person; they are productive in the labor market and/or in consumption; and they are created at a sacrifice of time and out-of-pocket resources.

En la síntesi de Grin \& Vallancourt (1997), la llengua és un tipus de capital humà (vg. també Grenier \& Vaillancourt 1983: 472-474), una forma de coneixement útil per als individus, de caràcter supercol-lectiu, el valor del qual augmenta, efectivament, a mesura que creix el nombre de persones que el fan servir, eixamplant-ne l'eficàcia comunicativa. En termes de comunitats humanes, la suma d'aquests capitals humans individuals és, de fet, una forma de capital social. Considerant l'externalitat de xarxa (positiva) i el caràcter col-lectiu, podem dir també que les llengües són, en realitat, béns hipercol-lectius, com ho fa de Swaan (2001: §2.1).

\subsubsection{La llengua-servei, la llengua-tecnologia i les externalitats negatives}

Més enllà de la llengua-bé, cal que considerem també la llengua com a servei, com s'esdevé en l'ensenyament de llengües i en les diverses formes de mediació lingüística (traducció, interpretació, subtitulació, localització...). En el primer cas, la voluntat d'accedir als beneficis de les llengües que garanteixen la capacitat de comunicar amb un nombre més gran de persones a tot arreu (les llengües hipercentrals) assegura un important contingent d'individus que han d'esmerçar temps, diners i esforços per a la seva formació lingüística i, per tant, l'oferta de serveis corresponent. Cal recordar, un cop més, que la incorporació d'aquestes persones a la comunitat d'usuaris de la llengua triada fa que aquesta obtingui un guany immediat en termes d'externalitat de xarxa i, per tant, que augmenti automàticament la seva capacitat d'atreure nous usuaris. 
Pel que fa al segon cas, és evident que, en el nou marc ecolingüístic globalitzat, bona part -si no la majoria- dels productes lingüístics que són al nostre abast (des del cinema o la literatura, fins als manuals d'instruccions o la retolació comercial, passant per les notícies de la premsa escrita o les pàgines d'Internet i arribant als béns de consum ordinaris) han estat objecte d'alguna mena d'intervenció lingüística, o l'han generat en els respectius processos de producció, d'etiquetatge, de transport, en les corresponents transaccions econòmiques, en les comunicacions que hi han donat lloc, en la publicitat i el marxandatge... Aquesta gestió lingüística, en la qual la llengua és directament una tecnologia, respondria al fet que, efectivament, els mercats són ja d'àmbit mundial, per la qual cosa els consumidors potencials són a tot arreu i cal adaptar-hi lingüísticament i culturalment l'oferta de productes i de serveis.

Hem de recordar que la ideologia subjacent a la globalització no té res a veure amb la preservació de la diversitat cultural, sinó que segueix estrictament, i per principi, la lògica del mercat. En realitat, la diversitat cultural i la diversitat lingüística són un obstacle per a la circulació de productes, d'una manera semblant a la diferent amplada de les vies dels trens o la variació en els formats que es fan servir per a la producció industrial. De fet, l'estandardització d'aquests últims té com a objectiu facilitar l'activitat empresarial, tot reduint la incertesa en la producció i la distribució de mercaderies i la prestació de serveis. Laplicació d'un criteri elemental de maximització dels beneficis fa pensar que les despeses d'adaptació lingüística dels productes i dels serveis (com qualsevol altre descompte de guanys) haurien de tendir a minvar i, en la mesura que això fos possible, a desaparèixer, des del punt de vista dels agents que creen i que gestionen els productes i els serveis que són susceptibles d'adaptació lingüisticocultural. Una bona manera de fer-ho és prioritzar les tecnologies més eficients. A la pràctica, això significa atribuir a les llengües un preu identificat amb llur valor d'ús, entès com la capacitat que tenen d'acostar els productes a un nombre més alt de potencials consumidors, i per tant de reportar beneficis amb un cost més reduït (recordem, un cop més, que una de les característiques del globalisme és la mercantilització). Hi ha, però, uns altres criteris que contribueixen a perfilar el valor de la llenguatecnologia, com ara el fet que el grup humà per al qual s'adapta el producte sigui capaç de garantir l'optimització de les transaccions (per exemple per la seva elevada capacitat adquisitiva, o pel seu pes demogràfic). En aquest context, la posició dominant de l'anglès com a llengua de la globalització és fora de discussió. Trobaríem després un feix de llengües competitives, en termes de mercat (el mandarí, el rus, l'hindi, l'espanyol, el portuguès...), que encara justificarien les despeses d'adaptació dels productes, i després un seguit de 
codis en una situació molt més compromesa. D'acord amb Skutnabb-Kangas (2004), "[...] only those 40-50 languages will remain in which people can, within the next few years, talk to their stove, fridge and coffee pot, i.e. those languages into which Microsoft software, Nokia mobile phone menus, etc., are being translated".

Val la pena tenir en compte també que la prestació de serveis lingüístics demana l'existència d'un capital humà previ, en la forma de coneixements lingüístics. Dit d'una altra manera: la llengua-coneixement és un bé previ a la llengua-servei. Una conseqüència òbvia és el fet que les persones que han adquirit com a materna una llengua d'ampla difusió (per un simple accident geogràfic, habitualment) tenen un magnífic benefici automàtic per aquest fet (que Breton [1998] anomena senyoratge). Grin (2004) ha caracteritzat un seguit d'efectes positius per als parlants de les llengües dominants en situacions de contacte, que poden ser extrapolats per als de les llengües dominants en el mercat lingüístic global:

- the 'privileged market effect': native speakers of the dominant language enjoy a quasi-monopoly over the markets for translation and interpretation into the dominant language, the market for second language instruction above a certain level, and the market for language editing all of which are tasks in which native-level skills are typically required;

- the 'communication savings effect': native speakers of the dominant language are spared the effort required to translate messages directed to them by speakers of other languages, since the latter will have made the effort to utter them in the dominant language in the first place; reciprocally, native speakers of the dominant language do not need to translate their messages into other languages;

- the 'language learning savings effect': native speakers of the dominant language do not need to invest time and effort in learning other languages; this amounts to a considerable savings. [...]

- the 'alternative human capital investment effect': the money not invested in foreign language acquisition can be diverted to other forms of human capital investment and give native speakers of the dominant language an edge in other areas;

- the 'legitimacy and rhetorical effect': native speakers of the dominant language will generally have an edge in negotiations or arguments with non-native speakers, because these always take place in their language. 
La naturalesa hipercol-lectiva de la llengua com a servei té alguns efectes paradoxals, tanmateix, que afecten el valor i les previsions de l'oferta i de la demanda. Per exemple, no hi ha cap motiu raonable per pensar que els cursos d'anglès (la llengua hipercentral per excel-lència) o les pràctiques de mediació lingüística que l'inclouen siguin més cars (tinguin un preu més elevat) que els cursos d'altres llengües o les pràctiques de mediació lingüística corresponent. De fet, l'externalitat de xarxa té, per definició, un valor negatiu per a les activitats de mediació lingüística: a mesura que augmenta el nombre d'usuaris d'una llengua, disminueixen les necessitats de traducció, evidentment (cf. de Swaan 1998: §2.2). En realitat, en aquests casos sí que opera la relació escassetat/augment de preu: la traducció en combinacions menys freqüents o la de llengües "exòtiques" tendeix a ser més cara. En el cas de la formació, l'augment de l'oferta en el cas de les llengües més demandades (les llengües hipercentrals) tendeix a anivellar els preus. A més, com després veurem, és força habitual que els governs considerin la formació lingüística un sector estratègic, i que la incorporin a l'ensenyament reglat obligatori.

\section{Planificació i preservació de l'hàbitat ecolingüístic}

Des d'un punt de vista estrictament economicista, aquests que acabem d'exposar tindrien l'aparença de criteris objectius per caracteritzar el nou mercat lingüístic global. Si entenem les llengües com uns mers instruments comunicatius que fluctuen (que han de fluctuar, en els termes del globalisme) en el lliure mercat, totes les decisions són força clares. Així, no és gens agosarat d'argumentar, per exemple, que l'ensenyament de llengües resulta més efectiu que la pràctica de la traducció, en societats multilingües. Colomer (1996), per exemple, tot aplicant la teoria dels jocs, conclou que, en comunitats de més de cinc llengües, l'ensenyament massiu d'una d'elles és socialment més eficaç (per garantir la màxima eficàcia comunicativa) que la traducció, i que l'ensenyament de dues llengües és més eficaç en les comunitats de més de deu llengües. Tanmateix, i més enllà del simple exercici intel-lectual, l'autor ens recorda que (1996: 182) "Here language is basically conceived as a tool for communication. [...] However, other dimensions of language, such as expression and its value as an element of culural enviornment, should be considered as a crucial complement of my evaluation [...]".

En efecte, la pretesa objectivitat de les perspectives exclusivament economicistes recolza, sovint, en la consideració que el valor de les llengües (el "preu") sigui mesurat només en termes mercantils, i no pas representacionals. Però, com ens recorda Grin (2006: 81): 
The "hypercollective" nature of language opens up some of the most challenging research avenues in language economics, but it does contain numerous pitfalls. For example, it has been used by some to defend, on allegedly economic grounds, support for the teaching of majority languages (Jones, 2000). However, the validity of this proposition crucially rests on one assumption, namely, that language is only a tool for communication (sometimes relabeled a "communication technology"). Sociolinguists have known for a long time that this does not do justice to the complexity of language in human experience.

Certament, més enllà del seu valor econòmic més fàcilment taxable, les llengües són també repositoris del coneixement acumulat de grups humans, el sediment de pràctiques comunitàries reiterades en el temps $i$, amb tota probabilitat, instruments que modelen la cognició individual (i, per tant, que reflecteixen les formes de cognició social i que contribueixen a mantenir-la). Des d'aquest punt de vista, la diversitat lingüística, d'una manera força semblant a la diversitat biològica, podria ser considerada un bé en ella mateixa. Segurament això mateix explica el fet que l'article 3 de la Declaració Universal sobre la Diversitat Cultural, adoptada en la $31^{\text {a }}$ sessió de l'Assemblea General de la UNESCO (http://unesdoc.unesco.org/ images/0012/001271/127160m.pdf), estableixi que la diversitat cultural és un factor de desenvolupament:

\section{ARTICLE 3 La diversité culturelle, facteur de développement}

La diversité culturelle élargit les possibilités de choix offertes à chacun; elle est l'une des sources du développement, entendu non seulement en termes de croissance économique, mais aussi comme moyen d'accéder à une existence intellectuelle, affective, morale et spirituelle satisfaisante.

No és sorprenent, per tant, que la Declaració reconegui entre les línies essencials del seu pla d'acció "sauvegarder le patrimoine linguistique de l'humanité et soutenir l'expression, la création, et la diffusion dans le plus grand nombre possible de langues". Val a dir, però, que no tots els estudiosos estan d'acord a considerar que la protecció de la diversitat lingüística sigui un bé en ella mateixa. De fet, encara que alguns especialistes consideren axiomàtica l'equiparació entre diversitat ecològica i diversitat lingüística (vg. p.ex., Skutnabb-Kangas \& Philipson 2008, Maffi 2001), i en dedueixen consegüentment uns drets lingüístics, en línia amb la declaració anterior, n'hi ha qui considera que l'establiment d'aquests drets lingüístics, especialment quan es basen en la consideració que les llengües tenen un valor intrínsec, mena a situacions inacceptables des d'un punt de vista liberal-democràtic (vg. p. ex., Boran 2003, Weinstock 2003). 
En qualsevol cas, i en termes pràctics, del que no hi ha dubte és que les comunitats humanes que disposen de capacitat per fer-ho, tendeixen a organitzar mecanismes d'intervenció per limitar els efectes de la lògica del mercat, nua i crua. Segurament ho fan perquè la tendència a la persistència en els comportaments -i no pas al canvi- és una constant en les societats humanes i, perquè, en últim extrem, sí que sembla fora de discussió la legitimitat de les comunitats per defensar allò que consideren un bé (hiper)col-lectiu, quan és amenaçat. De vegades, aquestes actuacions responen, efectivament, a alguna mena de decisió explícita que ha pres alguna agència d'alguna Administració, que fins i tot pot haver estat objecte de sanció legal. Quan és així, podem parlar, efectivament, d'autèntiques polítiques, tant si són paleses com encobertes i tant si responen a plans detallats com a conjunts de mesures (aparentment) inconnexes, que menen a resultats observables i justificables a partir d'elles mateixes. En tot cas, com apunta de Swaan (2001: 55), "[...] a community with an effective coordinating agency, such as a political authority of its own, is in a much better position to impose its policies than a collectivity that must rely on voluntary compliance".

Com havíem apuntat al començament d'aquest treball, les pràctiques de traducció representen una eina interessantíssima en aquesta mena de processos. En treballs anteriors, que ara revisem, ens hem referit a la conveniència d'intentar racionalitzar-los com a objecte d'estudi, considerant-los com a menes de control social, com també sembla assumir Meylaerts (2009: 8-9):

Parmi ces mécanismes de contrôle, la traduction joue un rôle de premier plan. La planification en matière de traduction institutionnelle fait effectivement partie intégrante de la politique de langue des sociétés multilingues, au point que cette dernière présuppose une politique de traduction. En d'autres termes, non seulement quelle(s) langue(s) peu(ven)t ou ne peu(ven)t pas être utilisée(s) mais aussi et nécessairement qu'est-ce qui peut (ne peut pas) être traduit par qui, quand et comment dans un context géo-temporel et institutionnel défini fait partie de la lutte pour 'qui est dedans' et 'qui est dehors'.

Des del nostre punt de vista (vg. Diaz Fouces 2001, 2002, 2005), aquests mecanismes fan referència a diverses àrees, com ara el balanç dels intercanvis dels fluxos lingüístics, la socialització professional del personal dedicat a la gestió lingüística i els aspectes lingüisticoestructurals. En aquest treball intentarem prioritzar el primer dels aspectes citats, tot presentant un primer esbós racional del catàleg de polítiques aplicades (i aplicables) a la gestió dels intercanvis lingüístics, amb la intenció de preservar el propi espai ecolingüístic. 
3.1. Les menes de polítiques: un intent d'aproximació racional

\subsubsection{Polítiques de regulació dels intercanvis externs}

Distingirem, en primer lloc, les polítiques de regulació dels intercanvis externs, l'objectiu de les quals seria mantenir i, en la mesura que sigui possible, augmentar el valor d'ús d'una llengua, entesa com un bé (hiper)col-lectiu, un capital social que és alhora capital individual de tots els membres de la comunitat d'usuaris. Parlem de comunitat d'usuaris, ja que, com és fàcil d'imaginar, les externalitats abasten també (amb més o menys intensitat) aquells individus que no es troben físicament al(s) estat(s) on la llengua és dominant. De tota manera, enteses com a polítiques públiques, és evident que estan orientades, principalment, al conjunt d'individus sobre els quals té competència una determinada Administració, tant si és regional com estatal o internacional. Les estratègies posades en joc poden tenir a veure amb la regulació de la balança d'intercanvis de productes culturals. Sense voler ser exhaustius, ens sembla que hi podríem abstreure els tipus següents, que apareixen numerats només per facilitar l'exposició posterior:

1. Les polítiques de projecció i de difusió exterior (de productes culturals) prenen la forma d'ajudes a l'exportació de béns lingüísticoculturals propis, per eixamplar-ne el mercat.

2. Les politiques de restricció a les importacions (de productes culturals) són estratègies proteccionistes que volen salvaguardar el valor de la llengua i per tant el capital social.

3. Les polítiques de promoció de l'ensenyament de la llengua pròpia a l'exterior intenten augmentar el valor de la llengua, a base d'estimular la integració de nous usuaris que creïn externalitats positives.

4. Les polítiques de promoció de l'ensenyament de llengües estrangeres contribueixen a augmentar el capital humà dels individus d'una comunitat de manera selectiva.

5. Les polítiques de foment de les traduccions de la pròpia llengua són mesures proteccionistes de suport a l'ús de la pròpia llengua-tecnologia.

6. Les polítiques de foment de la traducció a la pròpia llengua de productes externs valuosos contribueix a augmentar l'autoestima dels individus de la comunitat i a prevenir-hi la deserció lingüística.

Com veurem de seguida, cada parell de tipus (1-2, 3-4 i 5-6) representa, en realitat, dues perspectives d'un mateix fenomen. El primer (1-2) fa referència a allò que és habitual d'anomenar indústries culturals. Val la pena de recordar, en aquest moment, que el terme, generat al si de l'Escola de Frankfurt (i amb unes connotacions no gaire positives), va guanyar valor factual -més enllà 
de la dimensió filosòfica i sociològica- amb la posada en marxa d'acords comercials com ara el CUSFTA (Canada and United States Free Trade Agreement), l'article 2012 del qual defineix les indústries culturals com el conjunt dels sectors relacionats amb l'edició de llibres i de publicacions periòdiques, de la producció de vídeos i pel-lícules, la música i les emissions radiofòniques (vg. Neuwirth 2008). Estem parlant, naturalment, d'indústries en les quals als continguts lingüístics els correspon un paper fonamental. Un exemple paradigmàtic (i extrem) d'aquest primer tipus que ens ocupa és el que ens proporciona Redner (2004: 77). Es tracta del cas de la indústria americana del cinema i, en general, dels productes audiovisuals:

The purveyors of global culture, mainly American media companies, practice a commercial strategy that is often little short of cultural dumping. In order to create markets for their commodities they will give away for nothing or next to nothing shows that have already recouped their cost of production and reaped a handsome profit on the wide and wealthy American market. Such shows, once amortized, can then be exported around the world with the main purpose of building audiences, and so creating a demand for such cultural products as will eventually have to be paid for, vastly increasing the profits already gained. [...] It would be perfectly legitimate, and not necessarily infringe on free trade practices, to legislate against cultural dumping, as it has been done against every other kind of products-dumping.

Aquesta mena d'actuacions explicaria, efectivament, les respostes de caire proteccionista, per part d'aquelles comunitats que veuen envaï, d'una manera força agressiva, el seu propi espai ecolingüístic. Així, fa ja uns quant anys, el The New York Times destacava com a notícia el fet que tant França com Espanya estaven establint quotes d'exhibició per a les pel-lícules americanes, que il-lustren el nostre tipus (2). D'una manera força significativa, en el cas espanyol un dels mecanismes previstos era establir limitacions a la possibilitat d'emetre material doblat (vg. http://www.nytimes.com/1993/12/22/movies/ france-and-spain-impose-quotas.html i http://www.congreso.es/constitucion/ ficheros/leyes_espa/rdl_019_1993.pdf):

In Spain, the Parliament today approved a law saying that in towns with more than 125,000 inhabitants, every two days cinemas dedicate to American films must be followed by one day for European films. In smaller towns, cinemas will have to show one day of European movies for every three given of American films.

Proposed by the Socialist Government of Felipe Gonzalez, the law is intended to encourage European films at a time when Hollywood accounts for just less than 80 percent of the Spanish box office.

The legislation also imposes strict limits on dubbing. A license to dub any foreign film will be given only to a movie distribution company that has 
already shown European films earning about $\$ 143,000$ in box-office receipts during the year.

With the average European film earning about $\$ 64,000$ in Spain, the law effectively means that a company will have to show three European films before it can obtain a license to dub a Hollywood production. Most American movies in Spain are currently dubbed, and there is little public demand for films with subtitles.

Tot i que la legislació espanyola es va anar "suavitzant" (vg. http://www.boe. es/boe/dias/2001/07/10/pdfs/A24904-24909.pdf), la pròpia Unió Europea promou actualment diverses menes de mesures proteccionistes, en la forma de subvencions a la producció dels estats membres, com ho demostra la Decisió 1718/2006/EC del Parlament i del Consell d'Europa, més coneguda com el programa META 2007 (http://eur-lex.europa.eu/LexUriServ/site/en/ oj/2006/1_327/1_32720061124en00120029.pdf), que estableix com a objectius globals els següents:

(a) preserve and enhance European cultural and linguistic diversity and its cinematographic and audiovisual heritage, guarantee its accessibility to the public and promote intercultural dialogue;

(b) increase the circulation and viewership of European audiovisual works inside and outside the European Union, including through greater cooperation between players;

(c) strengthen the competitiveness of the European audiovisual sector in the framework of an open and competitive European market favourable to employment, including by promoting links between audiovisual professionals.

Lúltim dels tipus que proposem (6) suposa una perspectiva semblant. Perquè els parlants d'alguns grups lingüístics puguin accedir a una part significativa dels productes i dels serveis en la seva llengua, tot sovint han de trencar les regles del lliure mercat. Recordeu ara que a la citació anterior de SkutnabbKangas (2004) s'afirmava que només les comunitats amb una important densitat demogràfica o amb una gran capacitat adquisitiva atreuen les pràctiques de gestió lingüística per part dels grans agents del mercat. Correlativament, podem pensar que les pràctiques prestigioses de gestió lingüística es reserven per a les llengües econòmicament viables. Així que, de vegades, algunes comunitats "menys viables" es veuen obligades a desenvolupar estratègies proteccionistes. Un bon exemple és el cas de la localització al català, al gallec i al basc de dos productes de l'empresa Microsoft, el sistema operatiu Windows i el paquet ofimàtic Office, que van rebre importants subvencions per part dels respectius governs autonòmics, ja que l'empresa no la trobava rendible (recordeu la nostra citació anterior de Skutnabb-Kangas 2006). Si 
valorem el fet que tots els parlants de les respectives comunitats lingüístiques són també competents en la llengua espanyola, és evident que la subvenció no pot ser justificada en termes estrictament econòmics -si més no a curt termini-, sinó simbòlics. Incidentalment, és també força significatiu que en els tres casos esmentats el resultat fos un paquet LPI (Language Interface Pack, paquet d'interfície d'idioma) que calia instal-lar per utilitzar la interfície d'usuari localitzada, la qual cosa a la pràctica acaba per ser un "pedaç" parcial sobre una instal-lació "de debò" (http://www.elcorreogallego.es/index. php?idMenu=10\&idNoticia=44960, http://www.microsoft.com/spain/windowsxp/euskera.mspx i http://www.softcatala.org/el_windows_catala_amor_ impossible). Les polítiques proteccionistes prioritzen, evidentment, aquelles pràctiques de gestió lingüística connotades amb un valor simbòlic més gran, en aquest cas uns paquets informàtics d'ús global, que duen associats els valors de la modernitat i la tecnologia.

En un sentit complementari, i ja que els exemples anteriors feien referència a llengües subordinades, cal recordar, com ho fan O'Connell \& Walsh (2006), que la pràctica de la traducció des de la llegua subordinada duu associats uns valors força importants: "Translation into a minority language [...] may be necessary for its very survival, but translation from a minority language is usually important primarily in terms of status and prestige". De fet, aquesta mena d'exportació no només augmenta el valor simbòlic de la llengua, sinó també el seu valor real, com a bé hipercolllectiu. Un cop més, això explicaria l'existència d'estratègies proteccionistes en el cas de les comunitats subordinades, la visibilitat de les quals és més reduida. En aquest sentit cal interpretar les convocatòries periòdiques de subvenció per a la traducció del català a altres llengües d'obres literàries i de pensament de l'Institut Ramon Llull (vg. el Diari Oficial de la Generalitat de Catalunya núm. 5294, de 12.1.2009), o de la Institució de les Lletres Catalanes (http://cultura.gencat. net/ilc/) per al català. Com suggereix Cronin (2003: 167):

The problem for minority or endangered languages is not so much the fact of contact as the form of contact. Translation as a particular kind of contact is threatening and oppresive if the speakers of minority languages have not control over the translation process and cannot use translation as an enabling force but have to suffer it as a disabling intrusion.

I encara (Cronin 2003: 169):

Making knowledge and information available in minority langauges is not only an effective way of extending the way of usefulness of the languages concerned but it also allows the regional, the national and the global to be made local in a way that is politically enabling and allows for the beginning of a recovery of control over people's political, economic and cultural fates. 
Convé tenir present, però, que aquesta pràctica (el nostre tipus 5) no és exclusiva de les llengües subordinades: és força habitual en les llengües hegemòniques, molt especialment en el cas d'aquelles les característiques de les quals, com ara l'exigüitat del nombre de parlants, les fan poc competitives en el mercat global. Per això existeixen accions específiques en aquest sentit de l'Ireland Literature Exchange (http://www.irelandliterature.com/) per a l'irlandès. I també és força significatiu de verificar que les traduccions de la literatura en llengua neerlandesa són subvencionades en un $70 \%$ per la Fundació per a la Producció i la Traducció de la Literatura Neerlandesa (Nederlands Literair Productie- en Vertalingenfonds, http://www.nlpvf.nl/nl/over/) i els òrgans de govern de la comunitat flamenca (Linn 2006: 34). També el Ministeri d'Educació del Govern d'Islàndia disposa d'un Fons per a la promoció de la Literatura, que pretén, entre altres coses (http://bella.stjr.is/utgafur/ enskan.pdf),

[...] to promote Icelandic literature abroad so as to have Icelandic fiction published abroad in foreign languages, and supervision of the participation of Iceland in foreign cultural events and international cooperation in the field of literature. The fund may also make grants to translators of Icelandic literature into other languages in order to enable them to travel to Iceland to work on their translations and are responsible for conferences and work meetings of translators in Iceland.

El cas islandès ens serviria per exemplificar alhora els nostres tipus (5) i (6), ja que, al costat d'aquesta mesura, també manté un Fons per a la Traducció específic per a l'adaptació d'obres d'autors estrangers. Això no impedeix, de tota manera, que els sectors més joves de la població estiguin modificant substancialment les seves pautes de consum cultural, com ho demostra la preferència per la lectura de la sèrie Harry Potter directament en llengua anglesa (vg. Hilmarsson-Dunn 2006: 305).

El foment de la traducció de la pròpia llengua tampoc no és exclusiu de les llengües occidentals, com ho demostra la primera mesura d'aquesta selecció de propostes de política cultural del Ministeri de Cultura de Tanzània que reproduïm (http://www.tzonline.org/pdf/culturalpolicy.pdf):

1.2.2 Communities, private and public organisations shall be encouraged to research, write, preserve and translate vernacular languages into other languages. [...]

1.3.1 English shall be a compulsory subject in pre-primary, primary and secondary education levels and shall be encouraged in higher education. In addition the teaching of English shall be strengthened. 
1.3.2 The teaching of other foreign languages such as French, Portugese and Russian shall be encouraged.

Podem aprofitar aquest últim exemple per comprovar que la segona i la tercera de les mesures citades estan relacionades amb el tipus (4) de la nostra classificació. Com és fàcil d'imaginar, l'ensenyament de llengües estrangeres augmenta el capital humà dels individus i doncs, en certa mesura, el capital social col-lectiu. No és cap sorpresa que l'anglès, l'autèntica llengua franca mundial, sigui la més triada, encara que valgui la pena d'apuntar algun petit matís, com ho fa l'informe ELAN: Effects on the European Economy of Shortages of Foreign Language Skills in Enterprise de 2006 (el podeu consultar a http:// ec.europa.eu/education/languages/pdf/doc421_en.pdf):

Many respondents indicated that they viewed English as a key language for gaining access to export markets and frequent reference was made to its use as a lingua franca. However, the survey results, as well as comments from individual company respondents, suggest that the picture is far more complex than the much-quoted view that English is the world language.

The backlash against Russian which was noticeable in the former Soviet Bloc countries at the end of the last century is not in evidence and Russian is extensively used in Eastern Europe as a lingua franca (along with German and Polish). French is used to trade with partners in areas of Africa and Spanish is used similarly in Latin America. Individual respondents mentioned that English might be used for initial market entry, but longer-term business partnerships depended upon relationship-building and relationship-management and, to achieve this, cultural and linguistic knowledge of the target country were essential.

No hi ha dubte, en qualsevol cas, que una societat amb un bon nivell de destreses lingüístiques és potencialment més capaç d'enfrontar els desafiaments de la globalització i doncs de generar riquesa comunitària. De fet, ni tant sols es pot considerar que les persones que tenen com a pròpia la llengua franca internacional estiguin completament exemptes d'un coneixement raonable d'altres llengües i cultures, com posava de manifest fa pocs anys als Estats Units l'informe Education for Global Leadership: The Importance of International Studies and Foreign Language Education for U.S. Economic and National Security (Committee for Economic Development 2006 (a http://www. ced.org) i com assenyalava recentment el Director General de Traducció de la Comissió Europea (Lönnroth 2009: 4-5):

In 2007, the exports of goods from the United Kingdom to the whole of South America - an area with a population of 380 milion - were only marginally higher than those to Denmark - a country with a population of 5.5 million. 
This disappointing performance has been explained by the limited knowledge of Spanish and Portuguese in the United Kingdom business community.

En termes col-lectius, però, les polítiques d'ensenyament de llengües als administrats tenen un efecte col-lateral menys beneficiós, una externalitat negativa pel fet que una llengua amb la qual s'està competint pel propi espai ecolingüístic augmenti el valor d'ús a partir de la incorporació dels individus propis. Potser per això la selecció de la llengua que ha de ser privilegiada a l'ensenyament obligatori té sovint un valor estratègic que respon a interessos politicoeconòmics de més abast. Amb això podrien estar relacionades les oscil-lacions en l'actitud respecte a l'ensenyament de llengües als Estats Units (vg. Lantolf \& Sunderman 2001), la presència massiva de la llengua russa a l'ensenyament en els països del bloc comunista, després de la segona Guerra Mundial, o la incorporació recent de l'espanyol com a llengua obligatòria al sistema educatiu brasiler (i la nostra citació anterior de l'informe ELAN dóna pistes sobre els resultats i els motius, respectivament, d'aquestes dues circumstàncies). Ben al contrari, la promoció de l'ensenyament de la pròpia llengua a l'estranger (el nostre tipus 3), la missió que tenen assignada el Goethe-Institut, l'Instituto Cervantes o l'Instituto Camões és una font evident d'externalitats positives i doncs una eina per estintolar el propi espai ecolingüístic.

\subsubsection{Polítiques de regulació dels intercanvis interns}

Hem vist que els tipus presentats a l'apartat anterior responien a la voluntat de preservar l'espai ecolingüístic, tot evitant la fluctuació descontrolada del valor de la llengua pròpia. Per això, les actuacions corresponents volien obtenir, d'alguna manera, un equilibri extern. El tipus (4) en seria una excepció, d'alguna manera, perquè significa una mena d'actuació interna, en el si de la pròpia comunitat. En realitat, les formes més evidents de gestió de la diversitat lingüística es desenvolupen a l'interior dels ens politicoadministratius. Si tenim present que en el món actual és certament difícil trobar estats sobirans que presentin una homogeneïtat lingüística absoluta, cal assumir que en tots els casos allò que es privilegia és habitualment una única llengua o, si voleu, un únic espai ecolingüístic. Els governs i les administracions poden adoptar diverses perspectives per mantenir l'hegemonia d'una llengua dins l'espai de les seves atribucions. Una de les estratègies més òbvies és regular-hi els seus propis intercanvis comunicatius amb els administrats, allò que podem anomenar polítiques reguladores dels intercanvis interns, que ara intentarem glossar. Partim, com en el cas anterior, d'un esquema inicial que anirem desenvolupant 


\begin{tabular}{|l|l|l|}
\hline & Administració & Administrats \\
\hline \multirow{3}{*}{$\begin{array}{l}\text { Monolingüisme } \\
\text { institucional }\end{array}$} & a. No traducció & Traducció obligatòria \\
\cline { 2 - 3 } & b. Traducció assistencial & Traducció obligatòria freqüent \\
\cline { 2 - 3 } & c. Traducció oficial & Traducció obligatòria ocasional \\
\hline $\begin{array}{l}\text { Multilingüisme } \\
\text { institucional }\end{array}$ & d. Traducció total / No traducció & No traducció \\
\hline
\end{tabular}

En general, en contextos multilingües, les administracions poden assumir dues estratègies òbvies: la pràctica monolingüe o la multilingüe, amb tot un ventall de possibilitats intermèdies (cf. Meylaerts 2009: 14). Una administració multilingüe pura (d) es relaciona directament amb els administrats en la llengua que els és pròpia (o aquella que han triat). Per tant, significa una traducció sistemàtica de totes les actuacions (traducció total), o bé que aquestes siguin originàriament multilingües (no traducció). No són fàcils de trobar els exemples estrictes d'aquesta pràctica, ni tant sols en els països de (presumpte) multilingüisme igualitari. Potser la mateixa Unió Europea representaria un model relativament pròxim, ja que la legislació d'àmbit paneuropeu és multilingüe i el funcionament institucional també ho és. De tota manera això significa fer abstracció de totes les comunitats territorials que no tenen com a llengua pròpia una de les oficials de la Unió, a banda de l'immens contingent de persones immigrants i les comunitats no territorials (com la romaní). A més, cal no perdre de vista les tendències en el sentit d'una previsible reducció del (per a alguns) costós multilingüisme institucional europeu, si més no a nivell intern, que semblen força clares: com és sabut, només l'anglès, el francès i l'alemany són llengües d'ús intern factual de la Comissió i, de fet, si l'any 1997 els percentatges de documents redactats inicialment (drafts) en llengua anglesa representaven un 45,4\% del total de la feina de la Direcció General de Traducció, el 2004 eren un 62\%, i l'any 2008 suposaven ja un $72,5 \%$ (vg. http://ec.europa.eu/dgs/translation/publications/ brochures/translating_eu_brochure_en.pdf).

En el pol contrari (a) ens trobaríem aquelles administracions que obvien l'existència de qualsevol manifestació lingüística diferent de l'idioma reconegut com a oficial a l'interior de les pròpies fronteres. Com en el cas anterior, els exemples completament purs són difícils de trobar i tendeixen a coincidir amb sistemes polítics autoritaris. Fins i tot quan això s'esdevé, no és infreqüent que existeixin pràctiques coincidents amb el tipus (b), que de seguida descriurem. En realitat, les polítiques lingüístiques orientades als grups hegemònics d'individus i les que tenen com a objectiu aquells que no ho són, com a mínim a les democràcies liberals occidentals, són de naturalesa ben diferent: 
mentre que en el primer cas resulta esperable la prestació de serveis públics en la llengua pròpia d'aquells col-lectius, en el segon és força habitual optar per la traducció assistencial, com s'esdevé freqüentment amb els immigrants. Així, per a Bauböck (2001):

This is particularly important in institutional environments that are experienced as stressful, such as hospitals, police interrogations or courtrooms. In such institutions, immigrants may have a moral right not only to use their native language but also to be understood when they speak it. More generally, public policy in countries of immigration should accommodate immigrant languages by providing a broad range of translation and interpreter services, bilingual forms and ballots, information sheets and public broadcasting in immigrant languages.

Un exemple força notable és l'Ordre Executiva 13166 signada per l'expresident dels Estats Units Bill Clinton (Improving access to services for persons with limited English proficiency), que tenia com a objectiu garantir que els programes federals d'assistència disposessin de personal capacitat per atendre en la seva pròpia llengua aquelles persones que no tinguessin un coneixement suficient de l'anglès, o per oferir-los-hi serveis de traducció (http://www.justice.gov/crt/ cor/Pubs/eolep.php). Noteu que l'opció per la traducció i la interpretació assistencials és també l'estratègia que se segueix tot sovint en el cas de l'atenció als visitants estrangers, per exemple els turistes que demanen atenció policial, o hospitalària. De manera que, al costat del seu valor humanitari, aquesta mena d'actuació representa simbòlicament fer palès un grau inferior a la ciutadania complerta, que podria identificar-se amb la correspondència entre llengua oficial i llengua pròpia. Podríem dir que, en aquest cas, la traducció serveix també per establir una distància simbòlica entre les administracions i algunes persones i col-lectius, a qui deixa "marcats" com a "menys ciutadans (propis)". Observeu que la mateixa Unió Europea manté una pràctica (c) amb els ciutadans dels estats-membres (si més no, pel que fa a les llengües oficials) i una de (b) amb els immigrants (amb excepcions més afortunades, en què llurs llengües coincideixin amb les oficials de la Unió).

Des del punt de vista dels individus, els nostres tipus (a) i (b) també il.lustren allò que Branchadell (2005) anomena traducció obligatòria (mandatory translation), clarament relacionat amb el "communication savings effect" de Grin (2004) que citàvem més amunt, i que el mateix autor caracteritza de la manera següent (Branchadell 2005: 126): "Mandatory translation languages (MLT) are languages whose speakers do not have (or cannot exercise) the right to not translate their acts or words and the right to receive translations into their language of the acts of others". Una persona que té com a llengua pròpia alguna que no coincideix amb aquella que és oficial al lloc on 
es troba ha de mantenir una pràctica contínua de traducció dels seus actes, personals i públics. I, correlativament, pot esperar només en certs casos molt puntuals que l'Administració corresponent tradueixi les seves actuacions perquè li resultin comprensibles o proveeixi d'ofici serveis de traducció a determinades prestacions bàsiques, perquè hi pugui accedir. Amb les paraules de Meylaerts (2009: 11), "Ainsi, le monolinguisme institutionnel et l'idéologie monolingue reposent sur une combination judicieuse de traduction interdite et obligatoire. Lobligation de traduire forme la conditio sine qua non d'un système monolingue".

Significativament, la situació de les comunitats subordinades autòctones, aquelles que constitueixen els grups de ciutadans de dret d'un estat la llengua pròpia dels quals no és la dominant, acostuma a ser diferent de la dels immigrants, en aquests termes. En efecte, mentre que seria relativament comú, per exemple, que un immigrant marroquí acusat d'un delicte tingués a la seva disposició un intèrpret en ser detingut a la República francesa, un ciutadà francès de llengua occitana ben segur que no el tindria, amb l'argument que, com a ciutadà francès, hauria de ser prou competent en la llengua oficial del país (la qual cosa, efectivament, faria perdre el caràcter d'actuació assistencial).

El mateix exemple ens serveix per fer una altra observació complementària. Noteu que és perfectament imaginable el cas d'una llengua que es trobi en una situació de "molt bona salut" en un determinat espai, encara que un nombre significatiu de les persones que la tenen com a pròpia no la puguin fer servir per a la seva vida quotidiana, més enllà de les comunicacions informals i familiars. Aquest seria, per exemple el cas dels immigrants portuguesos a França, la llengua dels quals recupera tota la seva virtualitat funcional quan tornen de vacances a Portugal, el lloc on es donen les circumstàncies adequades per això: el seu propi hàbitat ecolingüístic. Aquest cas il.lustra clarament la importància de disposar-ne d'un de sanejat. De fet, un portuguès a França encara podrà tenir accés a un munt de productes culturals en la seva pròpia llengua (llibres, diaris, emissores de ràdio, televisió per satèl-lit, vídeos). Fins i tot es podrà adreçar a les autoritats europees en portuguès. Loferta de què disposaran els parlants de llengua occitana a la mateixa França, en canvi, serà molt i molt inferior, encara que, paradoxalment, es trobin en el territori on la seva llengua es va generar, i l'únic a tot el món on existeix una densitat demogràfica significativa d'usuaris, el seu hàbitat ecolingüístic, encara que la seva desestructuració i degradació siguin paleses.

El tipus (c) representaria una gradació que es correspon habitualment amb estats que disposen d'un cert grau de descentralització politicoadministrativa, com s'esdevé a Bèlgica, on la documentació oficial de les institucions 
federals té caràcter bilingüe, de manera que existeixen sempre traduccions en francès i neerlandès. Com és evident, l'oficialitat no acostuma a ser automàtica per a totes les minories. Encara que sigui una obvietat, cal recordar amb Henrard (2000) que, (només) a mesura que augmenta el nombre de ciutadans d'una minoria lingüística determinada, augmenta també -o, si més no, es fa més palesa- l'obligació de l'Estat de prestar-hi serveis en la llengua corresponent. A aquells grups que no arriben a assolir un pes demogràfic considerable, difícilment els són reconeguts drets lingüístics plens, que impliquen per definició l'accés a pràctiques colllectives, sinó que se'ls reserva, en el millor dels casos, la traducció assistencial. Així, en el cas del mateix exemple anterior Meylaerts (2009: 16) ens recorda que

La Belgique n'a en effet jamais considéré une traduction allemande dans ces domaines pour la minorité germanophone vivant dans les cantons de l'Est annexés en 1920 en exécution du traité de Versailles. Parallèlement, on n'a aucune indication d'une pareille politique traductionnelle vis-à-vis des minorités nouvellement immigrées en Belgique [...]

\section{Síntesi i conclusions}

En un món globalitzat, qualsevol comunitat humana pot veure amenaçada la continuïtat de les seves pràctiques lingüístiques. D’acord amb la metàfora ecològica, qualsevol grup ecolingüístic pot arribar a patir en algun moment una desestructuració del seu hàbitat, fruit d'una agressió directa o d'una alteració de les seves circumstàncies ambientals. Les causes també poden ser molt variades, i n'hi ha tant d'actives (com la coerció militar, política o econòmica) com de passives (com s'esdevé en el cas de l'absència de polítiques igualitàries en contextos de multilingüisme factual). Cal evitar, però, la impressió -errònia, a parer nostre- que la desestructuració dels hàbitats ecolingüístics sempre és conseqüència exclusiva de l'acció d'un agent exterior i que les restriccions a les pràctiques lingüístiques són respostes automàtiques. Com tots els canvis socials, les transformacions lingüístiques són processos complexos. No és difícil d'imaginar, per exemple, episodis d'abandonament massiu del propi codi (migracions lingüístiques) en favor d'un altre, sense que calgui posar a la pràctica cap mecanisme de coerció explícit. Les desigualtats en els processos de modernització, la (des)industrialització d'alguns espais o la desestructuració social poden conduir a situacions de pèrdua o de guany de prestigi i de valor d'ús que comportin canvis massius de les pautes de comportament lingüístic.

Per tal d'evitar aquesta mena d'amenaces, o per fer-hi front, diferents comunitats humanes hegemòniques i subordinades, nombroses i exigües, 
regionals i internacionals, han anat generant un seguit d'estratègies, moltes d'elles relacionades amb la planificació dels intercanvis lingüístics. En general, responen a decisions que han estat preses pels corresponents gestors públics, i que tot sovint han estat codificades en reglaments, en normatives $i$, de vegades, en lleis i en decrets. En aquest treball hem volgut presentar un primer intent de sistematització d'algunes d'aquestes estratègies. Val la pena d'observar que, en general, allò que pretenen és mantenir les condicions perquè unes determinades pràctiques lingüístiques continuïn essent viables en un espai ecolingüístic determinat, és a dir, per a preservar (i, quan és possible, per a eixamplar) el propi espai ecolingüístic. No és cap sorpresa que les pràctiques de traducció, en sentit extens, representin una eina fonamental per aquesta comesa, tant pel que fa a la relació amb la resta d'espais ecolingüístics com per a la gestió de l'espai propi. La presència en la nostra anàlisi de l'ensenyament de llengües també té un sentit obvi: per definició, les pràctiques de mediació lingüística (fora de les més simbòliques) s'esdevenen entre persones de llengua diferent, que altrament tindrien dificultats per comunicar-se. La relació entre aquestes dues manifestacions de la llengua-servei és palesa, com ho és la relació d'aquesta amb la llengua-bé.

$\mathrm{Ni}$ el catàleg teòric de mesures ni les eines conceptuals que han anat apareixent en els paràgrafs anteriors volen ser un inventari exhaustiu, de cap manera. Ans al contrari, volen ser una modesta contribució per a l'estudi de les interaccions en el nou sistema ecolingüístic global i, en la mesura que això sigui possible, per a la seva racionalització. La valoració de l'eficàcia a llarg termini d'aquestes mesures correspon, evidentment, a estudis de caire longitudinal, però passava, des del nostre punt de vista, per un intent d'abstracció prèvia de les eines disponibles.

Cal recordar, per últim, encara que sigui evident, que, des d'un punt de vista ètic, les pràctiques de restricció dels drets lingüístics (individuals i col-lectius) i les accions proteccionistes no són pas homologables. Les diverses opcions disponibles per regular els intercanvis interns representen una autèntica escala de compromís amb la diversitat. I, certament, no tenen el mateix impacte ecològic les pràctiques proteccionistes que posa en joc una comunitat hegemònica i les que implementa una de subordinada. També és veritat, però, que en un món globalitzat, les fronteres entre aquests dos tipus són cada cop més difícils de determinar i els parlants de llengües que ara són hegemòniques poden descobrir d'ací uns anys que també els cal traduir-se per fer-se entendre. 


\section{Bibliografia}

BAstardas-BoAdA, A. (2000) "Language Planning and Language Ecology: Towards a theoretical integration". Symposium 30 Years of Ecolinguistics. Versió electrònica: <http://www.scribd.com/doc/3025205/Language-Planning-andLanguage-Ecology-Towards-a-theoretical-integration?autodown=pdf>

BAuBÖCK, R. (2001) Public Culture in Societies of Immigration. Willy Brandt Series of Working Papers in International Migration and Ethnic Relations 1/01. Malmö: School of International Migration and Ethnic Relations - Malmö University. Versió electrònica: <http://dspace.mah.se: 8080/bitstream/2043/684/1/ Workingpaper101.pdf>

Boran, I. (2003) "Global Linguistic Diversity, Public Goods, and the Principle of Fairness". A: Kymlicka, W. \& A. Patten (eds.) Language Rights and Political Theory. Nova York: Oxford University Press. pp. 189-209.

Branchadell, A. (2005) "Mandatory Translation". A: Branchadell, A. \& L. M. West (eds.) Less Translated Languages. Àmsterdam/Filadèlfia: John Benjamins. pp. 125-135.

Breton, A. (1998) "An Economic Analysis of Language”. A: Breton, A. (ed.) Economic Approaches to Language and Bilingualism. Ottawa: Canadian Heritage. pp. 1-33.

Chesterman, A. (2006) "Questions in the Sociology of Translation". A: Ferreira Duarte, J.; A. Assis Rosa \& T. Seruya (eds.) Translation Studies at the Interface of Disciplines. Àmsterdam/Filadèlfia: John Benjamins. pp. 9-28.

CHISwick, B. \& P. Miller. (1995) "The Endogeneity between Language and Earnings: International Analyses”. Journal of Labor Economics 13: 2. pp. 246-288.

Colomer, J.M. (1996) "To translate or to learn languages? An evaluation of social efficiency". International Journal of the Sociology of Language 121. pp. 181-197.

Cooper, R.L. (1989) Language Planning and Social Change. Cambridge: Cambridge University Press.

Cronin, M. (2003) Translation and Globalization. Londres: Routledge.

DE SWAAn, A. (1998) In Care of the State: Health Care, Education and Welfare in Europe and the USA in the Modern Era. Cambridge: Polity Press.

DE SWAAn, A. (2001) Words of the World. The Global Language System. Cambridge: Polity Press.

Diaz Fouces, O. (1996) "Traducció i Language Planning". A: Orero, P. (ed.) Actes del III Congrés Internacional sobre Traducció. Bellaterra: Departament de Traducció. Universitat Autònoma de Barcelona. pp. 627-636.

DiAz FoucEs, O. (2001) "Cal planificar la mediació lingüística? L'exemple de Catalunya”. Revista de Llengua i Dret 36. pp. 121-156. 
DiAz FouCEs, O. (2002) "La planificació de la mediació lingüística". A: Diaz Fouces, O.; M. García González \& J. Costa Carreras (eds.) Traducció i dinàmica sociolingüística. Barcelona: Llibres de l'índex. pp. 85-110.

Diaz FoucEs, O. (2005) "Translation Policy for Minority Languages in the European Union. Globalisation and Resistance”. A: Branchadell, A. \& L. M. West (eds.) Less Translated Languages. Àmsterdam/Filadèlfia: John Benjamins. pp. 95-104.

FAirClough, N. (2006) Language and Globalization. Londres \& Nova York: Routledge.

FILl, A. (1998) "Ecolinguistics: State of the Art 1998". A: Fill, A. \& P. Mühlhäusler (eds.) 2001. The ecolinguistics reader: language, ecology and environment. Londres \& Nova York: Continuum. pp. 43-53.

Fishman, J.; C. Ferguson, \& J. Das Gupta (eds.) (1968) Language problems of developing nations. Nova York: John Wiley and Sons.

GRENIER, G. \& F. Vaillancourt. (1983) "An Economic Perspective on Learning a Second Language". Journal of Multilingual and Multicultural Development 4: 6 . pp. 471-483.

GRIN, F. (1994) "The Economics of Language: Match or Mismatch". International Political Science Review 15: 1. pp. 25-42.

GRIN, F. (2004) "On the costs of cultural diversity". A: van Parijs, P. (ed.) Linguistic Diversity and Economic Solidarity. Brussels: de Boeck-Universite. pp. 189-202.

GRIN, F. (2006) "Economic Considerations in Language Policy". A: Ricento, T. (ed.) An Introduction to Language Policy. Theory and Method. Òxford: Blackwell. pp. 77-94.

GRIN, F. \& F. Vallancourt. 1997. "La langue comme capital humain". Policy Options July/August 1997. pp. 69-72.

Haugen, E. (1972) "The Ecology of Language". A: Dil, A. S. (ed.) The Ecology of Language: Essays by Einar Haugen. Standford: Stanford University Press. pp. 325-339.

Haveman, R. H. (1987) "Policy Analysis and Evaluation Research after twenty years". Policy Studies Journal 16: 2. pp. 191-218.

HallidaY, M.A.K. (1990) "New Ways of Meaning. The Challenge of Applied Linguistics". Journal of Applied Linguistics 6. pp. 7-36.

HENRARD, K. (2000) "Language and the Administration of Justice: The International Framework". International Journal on Minority and Group Rights 7: 2. pp. 75-107.

Hilmarsson-DunN, A.M. (2006) "Protectionist Language Policies in the face of the forces of English. The case of Iceland". Language Policy 5. pp. 293-312.

KaTZ, M.L \& C. Shapiro. (1986) "Technology Adoptiv in the Presence of Network Externalities". Journal of Political Economy 94. pp. 822-841. 
KLOSs, H. (1967) "Abstand languages and Ausbau languages". Anthropological Linguistics 9: 7. pp. 29-41.

Lantolf, J. P. \& G. Sunderman. (2001) "The struggle for a place in the sun: Rationalizing foreign language study in the twentieth century". The Modern Language Journal 5(1): 5-25.

LINN, S. (2006) "Trends in the translation of a minority language. The case of Dutch”. A: Pym, A.; M. Shlesinger \& Z. Jettmarová (eds.) Sociocultural Aspects of Translating and Interpreting. Àmsterdam/Filadèlfia: John Benjamins. pp. 27-39.

LÖNNROTH,K.-J. (2009) "TheLanguageIndustryasaDriverforTechnologicalChange in a Global Economy". LISA Forum Asia - Global design and innovation. Taipei, 7 April 2009. Versió electrònica: <http://ec.europa.eu/dgs/translation/publications/presentations/speeches/20090407_language_industry_lisa_en.pdf>

MAFFI, L. (ed.) (2001) On Biocultural Diversity. Linking Language, Knowledge and the Environment. Washington: The Smithsonian Institute Press.

MeylaerTs, R. (2009) "Et pour les Flamands, la même chose: quelle politique de traduction pour quelles minorités linguistiques?" Meta 54: 1. pp. 7-21

Mufwene, S. M. (2002) "Colonisation, Globalisation and the Future of Languages in the Twenty-first Century". MOST Journal of Multicultural Societies 4: 2. Versió electrònica: <http://www.unesco.org/most/vl4n2mufwene. pdf>Mühlhäusler, P. (2000) "Language Planning and Language Ecology". Current Issues in Language Planning 1: 3. pp. 306-365.

Neuwirth, R. J. (2008) "The Culture Industries: From the Common Market to a Common Sense". A: Ward, D. (ed.) The European Union and the culture industries: regulation and the public interest. Hampshire: Ashgate. pp. 241-258

O'CONNELL, E. \& J. Walsh. (2006) "Translation and language planning in Ireland: Challenges and opportunities". Mercator International Symposium on Minority Languages and Research. University of Wales, Aberystwyth, October 2005. Versió electrònica: <http://www.aberystwyth.ac.uk/mercator/images/OConnellWalsh.pdf>

REDNER, H. (2004) Conserving cultures: technology, globalization, and the future of local cultures. Òxford: Rowman \& Littlefield.

SAntos, B. de Sousa. (2006) "Globalizations". Theory, Culture E Society 23: 393399. Versió electrònica: <http://www.boaventuradesousasantos.pt/media/ pdfs/Globalizations_Theory_Culture_and_Society_2006.PDF>

SkUtNABB-KangaS, T. (2004) Opening Plenary "The right to mother tongue medium education - the hot potato in human rights instruments". II Simposi Internacional Mercator: Europa 2004: Un nou marc per a totes les llengües? / II Mercator International Symposium: Europe 2004: A new framework for all languages? Tarragona. Versió electrònica: <http://www.ciemen.org/mercator/ pdf/simp-skuttnab.pdf> 
Skutnabb-Kangas, T. \& R. Phillipson. (2008) "A Human Rights Perspective on Language Ecology". A: Creese, A; P. Martin \& N.H. Horngerber (eds.) Ecology of Language. Vol. 9. Encyclopaedia of Language and Education. 2a edició. Nova York: Springer. pp. 3-14.

STEGER, M. B. (2005) Globalism: Market Ideology meets Terrorism. Lanham: Rowman \& Littlefield.

TourY, G. (1999) "Culture Planning and Translation". A: Álvarez, A. \& A. Fernández (eds.) Anovar/Anosar. Estudios de Traducción e Interpretación. Vigo: Universidade. pp. 13-25.

WeInRICH, H. (2001) "Economy and Ecology in Language". A: Fill, A. \& P. Mühlhäusler (eds.) 2001. The ecolinguistics reader: language, ecology and environment. Londres \& Nova York: Continuum. pp. 91-100.

Weinstock, D. M. (2003) "The Antinomy of Language Policy". A: Kymlicka, W. \& A. Patten (eds.) Language Rights and Political Theory. Nova York: Oxford University Press. pp. 250-270. 